\author{
Revista Brasileira de Educação do Campo \\ Brazilian Journal of Rural Education \\ ARTIGO/ARTICLE/ARTÍCULO \\ DOI: http://dx.doi.org/10.20873/uft.rbec.e12819
}

\title{
Perspectivas dos egressos do Curso de Licenciatura em Educação do Campo, Campus Arraias/Tocantins
}

\author{
Helena Quirino Porto Aires ${ }^{1}$, ID Luiz Bezerra Neto ${ }^{2}$ \\ ${ }^{1}$ Universidade Federal do Tocantins - UFT. Colegiado do Curso de Pedagogia. Avenida Juraídes de Sena Abreu, s/n. Setor \\ Buritizinho. Arraias - TO. Brasil. ${ }^{2}$ Universidade Federal de São Carlos - UFSCar.
}

Autor para correspondência/Author for correspondence: hequirino.uft@mail.uft.edu.br

RESUMO. O presente texto é um recorte da tese de Doutorado em Educação pela Universidade Federal de São Carlos-UFSCAR, em que apresenta um estudo sobre o Curso de Licenciatura em Educação do Campo (LEdoC) da Universidade Federal do Tocantins, Campus de Arraias, analisando em que medida as condições de sua materialização contribuem para a formação da classe trabalhadora. Este texto teve como objetivo analisar a materialização do Curso de Licenciatura em Educação do Campo sob a ótica dos egressos. Para tanto, empreendemos uma investigação que buscou responder a seguinte problematização: Quais as perspectivas dos egressos da LEdoC da UFT/campus de Arraias, Tocantins? Para tal buscamos desvelar o objeto de estudo a partir da realidade concreta, procurando relacionálo com a sociedade na busca da compreensão desse movimento da formação humana em sua totalidade. A coleta de dados ocorreu por meio de entrevistas semiestruturadas com 20(vinte) egressos da LEdoC no ano de 2019. Os resultados indicam que em relação aos egressos, o número de estudantes que concluíram ainda não é expressivo, dado que somente 37 (trinta e sete) sujeitos o fizeram. Por outro lado, os egressos revelam que o curso proporcionou contribuições importantes à formação pessoal, uma vez que muitos hoje têm outra visão da "Educação do Campo". Quanto à inserção ao mundo trabalho, o curso (e suas especificidades) ainda não está sendo contemplado em editais de seleções e concursos, municipais e estaduais, o que exige uma atenção sobre essas questões por parte principalmente dos interessados. Diante dos dados apresentados nesse estudo, é possível perceber que a LEdoC se empenha para que de fato sua proposta se materialize de forma satisfatória, no entanto, possui muitos desafios.

Palavras-chave: curso de licenciatura em educação do campo, egressos da educação do campo, perspectivas da educação do campo.

v. $6 \quad$ e12819




\title{
Graduates' perspectives of the Undergraduate program in Rural Education, Arraias Campus/Tocantins
}

\begin{abstract}
This text is an excerpt of the Doctoral thesis in Education at the Federal University of São Carlos-UFSCAR, in which it presents a study on the Undergraduate program in Rural Education (LEdoC) at the Federal University of Tocantins, Arraias Campus, analyzing in to what extent the conditions of its materialization contribute to the formation of the working class. This paper aimed to analyze the materialization of the Undergraduate program in Rural Education from the perspective of its graduates. Therefore, we undertook an investigation that sought to answer the following question: What are the LEdoC graduates' perspectives at UFT/Arraias campus, Tocantins? For this, we seek to unveil the object of study from the concrete reality, seeking to relate it to society in the search for understanding this movement of human formation in its entirety. Data collection took place through semi-structured interviews with 20 (twenty) LEdoC graduates in 2019. The results indicate that, in relation to the graduates, the number of students who completed it is still not expressive, given that only 37 (thirty-seven) of them completed the course. On the other hand, the graduates reveal that the course provided important contributions to their personal formation, since many now have another vision of "Rural Education". In relation to insertion in the labor world, the course (and its specificities) is still not being contemplated in selection and competition edicts, both municipal and state, which demands attention to these issues, especially on the part of those interested. Given the data presented in this study, it is possible to see that LEdoC strives to make its proposal materialize in a satisfactory way; however, it has many challenges.
\end{abstract}

Keywords: undergraduate program in rural education, graduates of rural education, rural education perspectives. 


\section{Perspectivas de los egresados del Curso de Licenciatura en Educación Rural, Campus Arraias/Tocantins}

RESUMEN. El presente texto es un extracto de la tesis de Doctorado en Educación de la Universidad Federal de São Carlos-UFSCAR, en el que se presenta un estudio sobre el Curso de Licenciatura en Educación Rural (LEdoC) de la Universidad Federal de Tocantins, Campus de Arraias, analizando en qué medida las condiciones de su materialización contribuyen a la formación de la clase trabajadora. Este texto pretende analizar la materialización de la Licenciatura en Educación Rural desde la perspectiva de los egresados. Por lo tanto, emprendimos una investigación que pretendía responder a la siguiente problematización: ¿Cuáles son las perspectivas de los egresados de LEdoC de la UFT/campus de Arraias, Tocantins? Para ello buscamos desvelar el objeto de estudio desde la realidad concreta, buscando relacionarlo con la sociedad en la búsqueda de la comprensión de este movimiento de formación humana en su totalidad. La recogida de datos se produjo a través de entrevistas semiestructuradas a 20 (veinte) egresados de la LEdoC en el año 2019. Los resultados indican que, en relación con los egresados, el número de estudiantes que han completado no es todavía expresivo, dado que sólo 37 (treinta y siete) sujetos lo han hecho. Por otro lado, los egresados revelan que el curso brindó importantes aportes a la formación personal, ya que muchos tienen ahora otra visión de "Educación Rural". En cuanto a la inserción en el mundo laboral, el curso (y sus especificidades) aún no está contemplado en los edictos de las selecciones y concursos municipales y estatales, lo que requiere atención sobre estas cuestiones, especialmente por parte de los interesados. Dados los datos presentados en este estudio, es posible darse cuenta de que la LEdoC se esfuerza para que de hecho su propuesta se materialice de forma satisfactoria, sin embargo, tiene muchos retos.

Palabras clave: curso de licenciatura en educación rural, graduados en educación rural, perspectivas de la educación rural. 


\section{Introdução}

Nas últimas décadas, o Brasil passou por grandes mudanças nos aspectos políticos, econômicos e educacionais. Um dos principais marcos - e talvez o mais importante - foi a promulgação da Constituição Federal de 1988, especialmente por proporcionar uma nova reorganização da educação que, por sua vez, suscitaram muitas reformas educacionais que permitiram a uma grande parte da população brasileira o acesso à educação como um direito social.

Todavia, nos termos em que prevê uma educação para "todos", ainda não foi possível a sua efetivação plena, tendo em vista os milhares de brasileiros que ainda se encontram fora da escola, inclusive aqueles que vivem no campo. Ademais, as problemáticas existentes vão desde as questões de infraestrutura àquelas relacionadas à formação humana - que assolam as escolas públicas brasileiras na garantia ao acesso -, à permanência e a qualidade da educação, maiormente naquelas situadas no campo.

Apesar dos entraves para a efetividade das reformas educacionais no Brasil, é notório que o Ministério da Educação (MEC) vinha efetivando nas últimas décadas, várias políticas/ações educacionais voltadas para o campo.
Dentre elas, podemos destacar as Diretrizes Operacionais para a Educação Básica do Campo (Brasil, 2002b) - que abrangem toda organização da educação das escolas localizadas no campo - e o Programa de Apoio à Formação Superior em Licenciatura em Educação do Campo (Procampo), cujo objetivo é apoiar e implementar os cursos de licenciatura em educação do campo nas instituições públicas de ensino superior de todo o país, voltados especificamente para a formação de educadores para a docência nos anos finais do ensino fundamental e ensino médio nas escolas rurais.

Vale mencionar que essa conquista no âmbito da Educação no Campo veio como uma resposta às reivindicações dos movimentos sociais desde a década de 1980, por uma educação que atenda às necessidades das populações do campo. Em outras palavras, essa luta foi justamente para compensar um pouco das mazelas que existiam e ainda permanecem nas escolas brasileiras localizadas no campo.

Sobre essas considerações, Oliveira (2017) faz alguns apontamentos importantes sobre as políticas públicas para a Educação no Campo, enfatizando que a criação de uma determinada política corresponde a um conjunto de demandas gerais para o campo. Todavia, as ações e 
programas são determinados pelo governo daquele contexto, podendo cumprir tais objetos de diversas formas, bem como,

pode atender a uma formação apenas de mão-de-obra mantendo a ordem vigente; pode ser para ampliar a alienação do trabalhador de seu resultado de trabalho; pode ainda servir à recriação camponesa e a construção de ações de autonomia para essas comunidades; pode servir simplesmente a uma formação para a inserção do agricultor familiar no mercado. (Oliveira, 2017, p. 16).

Partindo dessas premissas, ficam evidentes as caraterísticas da sociedade capitalista que estamos inseridos, e algumas questões sobre políticas/programas/ações que sempre serão estabelecidas nesse viés: quem controla (Estado) e quem é controlada pelo Estado (classe trabalhadora).

Mesmo com esse intuito da sociedade capitalista, convém mencionar que, em termos de legislação, muitos avanços já ocorreram no que se refere à garantia da educação como um direito social (Locatelli, Nunes \& Pereira, 2013). No entanto, é importante lembrar que, ainda se faz necessário a determinação das/nas lutas de classes para o aperfeiçoamento e a manutenção desses avanços, visto que, o panorama atual das políticas públicas educacionais se encontra instável, sobretudo, após o golpe parlamentar de 2016 ${ }^{\mathrm{i}}$, momento em que a elite política e econômica se voltou para a destruição dos direitos duramente conquistados pela classe trabalhadora.

No que tange à Educação Superior, destaca-se a criação (a partir de 2006) a expansão de cursos de Licenciatura em Educação do Campo em várias universidades brasileiras. Dentre essa ampliação, o Estado do Tocantins foi contemplado com o curso de Licenciatura em Educação do Campo com habilitação em Artes e Música nos campus de Arraias e Tocantinópolis (2014), com o mesmo objetivo dos demais: formar profissionais para atuar em escolas localizadas no campo.

Para atendimento dessa população composta majoritariamente de trabalhadores do campo, a proposta do curso de Licenciatura em Educação do Campo no Brasil funciona por meio da Alternância, e seu processo de ensino e aprendizagem ocorre em alternância de espaços e saberes: Tempo Universidade (TU), compreendidos como espaços onde se trabalha parte da carga horária do curso, envolvendo atividades mais de teor teórico tendo como ponto de partida a ementa de cada disciplina; e, Tempo Comunidade (TC), entendido como espaço onde se dá continuidade aos estudos com a outra parte da carga horária de vinte horas do curso com atividades de teor mais práticas. 
Ademais, a Educação por Alternância possibilita a conexão de conhecimentos nesses espaços, permitindo também a valorização das histórias, dos saberes, das culturas dos sujeitos envolvidos nesse processo, tendo em vista que essa dinâmica do curso corrobora para que o sujeito consiga estudar e, ao mesmo tempo, continuar trabalhando e residindo em suas comunidades (muitas delas distantes do município onde se localiza a universidade).

Portanto, este texto tem como objetivo analisar a materialização do Curso de Licenciatura em Educação do Campo sob a ótica dos egressos. Para tanto, empreendemos uma investigação que buscou responder a seguinte problematização: Quais as perspectivas dos egressos da LEdoC da UFT/campus de Arraias, Tocantins? Para tal buscamos desvelar o objeto de estudo a partir da realidade concreta, procurando relacioná-lo com a sociedade na busca da compreensão desse movimento da formação humana em sua totalidade.

\section{Perspectivas teóricas e metodológicas}

No que tange aos caminhos teóricos escolhidos, o materialismo histórico dialético é uma vertente que contribui para desvelar a realidade, busca entender o contexto a partir de suas contradições e relações entre a singularidade, particularidade e universalidade. Em outras palavras, caracteriza-se pelo movimento do pensamento por meio da materialidade histórica da vida do ser humano em sociedade. Nesse sentido, Masson (2012) ressalta que essa corrente tende a compreender o real a partir do desenvolvimento histórico e de sua origem, apreendendo os indicadores que possibilitam sua compreensão na totalidade, e isso ocorre porque o "método dialético leva em conta essa ação recíproca e examina os objetos e fenômenos buscando entendê-los numa totalidade concreta" (Gadotti, 2001, p. 24). E, nesse desiderato, para estudo dos egressos do curso de Licenciatura em Educação do campo que é importante pesquisar o lugar, as categorias e os contextos que emergem a sua materialização.

A parir dessas considerações, a perspectiva teórica foi associada a outro instrumento como entrevistas semiestruturadas com 20 (vinte) egressos do curso de Licenciatura em Educação do Campo (LEdoC) no campus de Arraias, realizadas no ano de 2019. As respostas dos entrevistados foram gravadas em áudio e depois transcritas. Trata-se de uma metodologia que permite que se descubra e se relacione vários acontecimentos durante a realização do estudo, tornando assim, mais precisas as informações pesquisadas e 
necessárias para o alcance dos objetivos da pesquisa.

$\mathrm{Na}$ mesma linha de compreensão, Martins (2006, p. 10-11) aponta que:

... se queremos descobrir a essência oculta de um dado objeto, isto é, superar sua apreensão como real empírico, não nos bastam descrições acuradas (escritas, filmagens, fotografias etc. !!), não nos bastam relações íntimas com o contexto da investigação, isto é, não nos bastam fazer a fenomenologia da realidade naturalizada e particularizada nas significações individuais que lhes são atribuídas. É preciso caminhar das representações primárias e das significações consensuais em sua imediatez sensível em direção às descobertas múltiplas determinações ontológicas do real.

Para a apresentação das análises, utilizamos trechos das conversas ou recortes dos protocolos das transcrições das entrevistas, contidos nos registros verbais para elucidar a fundamentação teórica. A partir das análises, os resultados foram organizados de forma a possibilitar a verificação e contemplação dos objetivos estabelecidos para esta pesquisa.

\section{Os maiores desafios do curso de Licenciatura em Educação do Campo da UFT/Arraias}

Aqui será apresentada uma síntese dos maiores desafios vivenciados pelos sujeitos da LEdoC. Evidentemente que não é uma tarefa muito fácil trabalhar com formação de educadores, ainda mais quando pensamos a educação que é ofertada nos moldes da sociedade capitalista. Isso porque, trabalhar de maneira contra-hegemônica é algo muito complexo, como diz Saviani (2008), principalmente pelo fato de a classe dominante não dar importância a uma escola que provoque uma transformação desse status quo. Pelo contrário, empenhase para a manutenção dela em seu poder.

Nesse sentido, são muitos desafios postos à educação da classe trabalhadora:

A impossibilidade da universalização efetiva da escola, a impossibilidade de todos ao saber; a impossibilidade de uma educação unificada, o que leva a se propor um tipo de educação para uma classe e outro tipo para outra classe ou então uma mesma educação para todos, porém, internamente, de fato diferenciada para cada classe social, e assim sucessivamente. (Saviani, 2008, p. 255).

E, quando analisamos a escola do campo, a formação do sujeito que vive tanto no processo de escolarização da educação básica como na educação superior, esses desafios se tornam maiores. A legislação prevê que o acesso é para todos, no entanto, há contradições em sua efetivação, justamente pelas características intrínsecas à sociedade.

Essas contradições também são evidenciadas na materialização do curso da LEdoC quanto temos as seguintes situações: 
1) Dificuldades de acesso à universidade e às comunidades integradoras (transporte);

2) Enfrentamentos na conciliação entre o trabalho e o curso de Licenciatura em Educação do Campo;

3) Problemas na acomodação no período do tempo universidade;

4) Ausência ou inadequação de acomodação no tempo comunidade;

5) A construção da proposta de Educação por Alternância que atenda o curso, a formação do indivíduo a partir da realidade dos envolvidos;

6) Ausência de recursos financeiros para realização das atividades no tempo comunidade, pois os custos para realização dos encontros são feitos por estudantes e professores; e,

7) A falta de oferta de disciplinas no curso para atender os estudantes com pendências.

É possível verificar nessa pesquisa os desafios que o sujeito da classe trabalhadora enfrenta para ter o acesso, a permanência com qualidade no curso. Dessa forma, Saviani (2008) enfatiza que os desafios perante a educação, só serão superados se houver uma superação deste modo de sociedade.

As perspectivas do curso de Licenciatura em educação do Campo da UFT-Arraias
De acordo com Aires (2020), o curso da LEdoC Arraias/UFT possui diversos enfrentamentos, principalmente por ser novo e estar em busca constante por sua existência e consolidação. No entanto, já conquistou espaços e possui elementos que demonstram sua importância para a classe trabalhadora por possuir/prever/garantir:

$\mathrm{O}$ acesso do sujeito da classe trabalhadora à educação superior;

A proposta do curso de formação de professores via Educação por Alternância, além de ser uma forma metodológica, pedagógica e epistemológica que viabiliza a grande parte da classe trabalhadora estudar e trabalhar;

Há elementos em sua materialização que indicam uma formação humana pautada na transformação a partir da realidade, isso implica em pensar que tal concepção será levada para atuação no campo ou na cidade;

$\checkmark \quad$ Concebe a teoria e prática numa via de mão dupla na mediação do conhecimento nos tempos/espaços de aprendizagem-universidade e comunidade;

A efetivação de atividades nos tempos da universidade e nos tempos da comunidade numa perspectiva contra hegemônica;

Perspectivas de professores atuando em escolas no campo com 
formação superior, contribuindo para com os sujeitos que residem no campo;

Consolidação do curso de formação de professores para que de fato este se institucionalize nas universidades e institutos federais; e,

O curso em análise recebeu avaliação do MEC (2019) com nota de Excelência, nota 5.0 (numa escala de 1 a 5), fato muito importante diante do momento político delicado que estamos vivendo.

Nesse sentido, compreendemos que a LEdoC não assegura uma formação aos sujeitos em sua totalidade, por apresentar limitações em sua materialização dadas às condições da estrutura. No entanto, sabemos que sem ela, setores da classe trabalhadora que trabalha e vive no campo, tampouco teria a oportunidade de frequentar uma universidade, porque entendemos que a educação projetada pela burguesia para seu uso próprio é inseparável do modelo de sociedade burguesa. Ela contribui para amenizar os conflitos, incutir leis e normas, fazer cumprir a ordem e assim, para que os trabalhadores aceitem as relações sociais de exploração às quais estão submetidos (Ribeiro, 2013, p. 307).

\footnotetext{
Perspectivas dos egressos do curso de Licenciatura em Educação do Campo
}

Neste subitem versaremos sobre as perspectivas dos egressos do curso de Licenciatura em Educação do Campo, verificando suas contribuições pessoais e em relação a sua inserção no mundo do trabalho, especificamente nas áreas de formação - Artes Visuais e Música.

Para essa compreensão, faz-se salutar mapear as entradas de alunos (quantidades e em quais semestres) para visualizar quantos já possuem tempo mínimo para integralização do curso e quantos já concluíram seus estudos.

Registra-se que o edital que a LEdoC da UFT/Arraias concorreu junto ao MEC e previa que, ao final de um triênio, 360 matrículas fossem efetivadas. Deste modo, a primeira turma ingressou no primeiro semestre de 2014 com um total de 120 alunos; no ano seguinte (2015) foram realizadas duas seleções para 60 vagas cada; e, no $3^{\circ}$ ano (2016), outras 120 vagas foram disponibilizadas em única seleção novamente, fechando o previsto/pactuado. Após esse período, o número de vagas e entradas foi reduzido para 60 por ano, e, em 2018/2 ${ }^{\circ}$ para 40 ingressantes anuais.

O tempo mínimo para integralização do curso é de 4 (quatro) anos (8 semestres). Em virtude da greve que ocorreu em 2015, o curso atrasou um semestre e as primeiras turmas acresceram um semestre no 
cômputo para sua integralização. Vejamos

os números do curso no ano de 2019.

Tabela 1- Alunos matriculados na LEdoC da UFT/Arraias.

\begin{tabular}{|c|c|c|c|c|}
\hline Ano/Semestre & Ingressantes & Matriculados & Formados & $\begin{array}{lr}\text { Semestre } & \text { mínimo } \\
\text { previsto } & \text { para } \\
\text { integralização do curso }\end{array}$ \\
\hline $2014 / 1^{\circ}$ & 120 & 50 & 34 & $2018 / 1^{\circ}$ \\
\hline $2015 / 1^{\circ}$ & 60 & 39 & 03 & $2019 / 1^{\circ}$ \\
\hline $2015 / 2^{\circ}$ & 60 & 37 & - & $2019 / 2^{\circ}$ \\
\hline $2016 / 2^{\circ}$ & 120 & 52 & - & $2020 / 2^{\circ}$ \\
\hline $2017 / 1^{\circ}$ & 59 & 43 & - & $2021 / 1^{\circ}$ \\
\hline $2018 / 1^{\circ}$ & 60 & 49 & - & $2022 / 1^{\circ}$ \\
\hline $2018 / 2^{\circ}$ & 41 & 41 & - & $2022 / 2^{\circ}$ \\
\hline Total & 520 & 311 & 37 & \\
\hline
\end{tabular}

Fonte: Elaborado pelos autores a partir de dados formatado pela Secretaria Acadêmica em 06/02/2019 e Secretaria LEdoC, UFT/Arraias em 12/12/2019.

De acordo com os dados disponibilizados pela Secretaria Acadêmica em 06/02/2019 e Secretaria LEdoC da UFT/Arraias, em 12 de dezembro de 2019, do total de ingressantes dos editais de processos seletivos de 2014 e $2015 / 1^{\circ}, \quad$ somente 37 sujeitos conseguiram concluir o curso. Ou seja, de 180 ingressantes, apenas $20 \%$ se formou nos prazos previstos. Esse número merece atenção.

Devido ao formato do curso e da oferta das disciplinas (nas férias, feriados e finais de semana), quando um aluno reprova, possui poucas chances de cursar a disciplina em período distinto. Essa situação contribui para essa realidade de não integralização do curso dentro do prazo mínimo, como registrado pelo estudante L (LEdoC, 2019) a seguir:

... em relação às disciplinas que não consegue passar: teria um período para você vir fazer elas. Não só agora em julho ou janeiro ... você tem outras disciplinas pra fazer e nesse período você choca e não pode fazer. Então eu acho que nesse ponto é uma conversa assim que eu penso. Conversei com alguns alunos que estudam na UNB e tem um período para você ir lá isso aqui, essa via, pode ser com outra matéria, mas tipo cinco, dez dias condensados; não esse problema de chocar horário com disciplinas; deveria ser melhor.

Além desse choque de horários de disciplinas no período do Tempo Universidade, as características dos estudantes não permitem cursar disciplinas em outros cursos, pois como já dito em outras partes do texto, moram distantes da 
cidade de Arraias, como também possuem disciplinas muito específicas do próprio curso de Educação do Campo nas áreas de Artes e Música que não são ofertadas por outros cursos. Ademais, como estão matriculados em um semestre anterior devido ao atraso de calendário por uma greve ocorrida no mês de atividades intensivas que não foram repostas, o sistema da universidade não permite a matrícula em dois semestres letivos concomitantemente.

Nesse sentido, uma das possíveis sugestões para aumentar o quantitativo de concluintes do curso seria pensar numa organização sistematizada para a oferta pelo próprio curso de disciplinas aos estudantes que não conseguissem aprovação, nos períodos regulares e/ou em dias e horários especiais, como por exemplo, no período noturno. Além desses, certamente existem outros fatores que levaram a não integralização dos estudos desses alunos no período mínimo do curso e que necessitam de estudos mais precisos sobre essa questão.

Dando continuidade à pesquisa, indagarmos aos egressos sobre o tempo de conclusão no curso de Licenciatura em Educação do Campo, e obtivemos as seguintes respostas:

- Há mais de um ano, a colocação de grau foi dia 30 de novembro de 2018. (Egresso A, LEdoC, 2019).
- Tem um ano. Eu colei grau em novembro de 2018. (Egresso B, LEdoC, 2019).

- Eu colei grau dia 30 de outubro de 2018. (Egresso C, LEdoC, 2019).

- Há um ano. (Egresso D, LEdoC, 2019).

- Há pouco mais de um ano. (Egresso E).

- Sou formada no curso de Licenciatura em Educação do Campo há um ano e um mês. (Egresso F, LEdoC, 2019).

- Sou formada desde a primeira colação de grau, ou seja, desde outubro de 2018 (Egresso G, LEdoC, 2019).

- Um Ano. (Egresso H, LEdoC, 2019).

- Sou formado há 1 e 2 meses. (Egresso I, LEdoC, 2019).

- Eu sou formado no Curso de Licenciatura em Educação do Campo há mais de 1 ano. (Egresso J, LEdoC, 2019).

Quando analisamos o tempo de conclusão do curso pelos egressos, percebemos que todos já se formaram há mais de um ano na LEdoC. E, muitos deles já poderiam estar contribuindo para com a formação de sujeitos do campo, no sentido de atender uma das propostas do curso, que é colaborar com formação dos povos que vivem no campo.

Questionamos os egressos do curso de Licenciatura em Educação do campo para sabermos se estão atuando como profissionais da Educação no Campo ou se continuam com seus trabalhos fora da educação. Assim, eles se manifestaram:

Estou atuando sim, como professora de Libras, contrato temporário. (Egresso A, LEdoC, 2019). 
Não. Eu trabalho na Secretaria Municipal, estou na supervisão escolar, mas atuando na educação infantil com turmas de $1^{\circ}$ ao $5^{\circ}$ ano. (Egresso B, LEdoC, 2019).

Eu já atuei como voluntária, desenvolvendo projetos. Agora não. Mas já atuei. Atualmente estou somente estudando para concursos mesmo. (Egresso C, LEdoC, 2019).

Atuo em algumas partes. Quando eu estou trabalhando, aproveito as discussões para a elaboração de algum material para as escolas, aquelas que estão situadas no campo. Mas atuando na área mesmo, não. $\mathrm{Na}$ coordenação pedagógica nas escolas do campo. Então, a gente aproveita algumas leituras, alguns textos pra discutir algumas questões que voltam para as questões das políticas públicas. (Egresso D, LEdoC, 2019). Indiretamente sim, mas como coordenador de duas escolas da área rural. Ainda não tive a oportunidade de exercer a docência das habilitações pelas quais fui formado no curso. (Egresso E, LEdoC, 2019). Ainda não atuo na área da Educação do Campo. (Egresso F, LEdoC, 2019).

Não atuo na área. (Egresso G, LEdoC, 2019).

Não. (Egresso H, LEdoC, 2019).

Não. (Egresso I, LEdoC, 2019).

Não. Desde que conclui o curso não atuo na área da Educação, trabalho apenas com vendas. (Egresso J, LEdoC, 2019).

Pelas respostas dos egressos, do total de 10 participantes, somente 04 dos entrevistados estão atuando - mesmo que indiretamente - com a formação dos sujeitos que vivem no campo. Um dado importante nas respostas dos egressos é que alguns deles estão atuando na área da Educação não propriamente em escolas localizadas no campo, mas estão em funções de coordenação/supervisão em secretarias municipais que contribuem para a Educação no Campo.

Essas informações geraram outros questionamentos a partir dos que já apontamos na introdução desta pesquisa: Nesse sentido, seria importante saber se o curso atende às necessidades dos povos do campo? Como inserir os egressos no mundo do trabalho, se a proposta do curso é por área de conhecimento e a realidade das escolas públicas não contempla essa perspectiva? Como participar de seleções de contratos e concurso públicos com uma formação "Curso de Licenciatura em Educação do Campo com Habilitação em Artes Visuais e Música”? Será que o curso contribuirá para a formação profissional dos sujeitos da classe trabalhadora de fato?

Nesse sentido, os egressos foram questionados se há concursos públicos que contemplem a sua área de formação, e com base nas informações deles foi possível verificar que a Educação do Campo e o curso de Educação do Campo com habilitação em Artes Visuais e Música ainda encontra barreiras nesses processos de seleção. A partir das respostas pudemos perceber que isto ainda é um desafio a ser enfrentado no sentido de assegurar na prática algumas das conquistas obtidas pelos sujeitos da classe da trabalhadora e do campo. Essa preocupação também é 
relatada por Brito e Molina (2016, p. 1742) ao destacarem que:

Outro ponto importante a ser trabalhado é a inserção no mundo do trabalho e especificamente nas áreas de formação da Licenciatura em Educação do Campo uma questão que suscita o aprofundamento é quais as estratégias que devem ser adotadas por esses egressos para inserção nas escolas do campo especificamente na área para o qual foram formados (Ensino Fundamental maior e Médio).

A inserção dos egressos no mercado de trabalho via seleções e concursos públicos é uma inquietação dos egressos, como relata um deles ao ser questionado sobre isso: "Ainda não. Os concursos que já saíram, nenhum, que já vimos tem pra área de Educação do Campo" (Egresso A, 2019). Essa situação nos faz retomar a questão da formação de professores por área de conhecimentos visto que, nesse formato, os egressos enfrentarão alguns desafios.

As nossas análises acerca disso coadunam com as falas dos egressos:

Não. Nenhum concurso que eu já pesquisei (até com interesse de me candidatar nessas vagas) não possui vagas nessa área. Acredito que falta de divulgação para o público, para os municípios, para as secretarias de educação tanto estadual como municipal. Então, assim, a falta de divulgação, não há essa divulgação. Então muitos municípios, muitas secretarias de educação desconhecem esse curso. (Egresso B, LEdoC, 2019).
Já saiu somente na área de Artes. Na

Educação do Campo não. Contemplam somente professores de Artes Visuais, não vem esclarecendo se é Educação do campo e Artes Visuais. (Egresso C, LEdoC, 2019).

Quando partimos para as questões de concursos públicos, as habilitações do curso do curso se tornam um entrave, pois nas seleções que já surgiram, tais habilitações não foram contempladas. E mais uma vez, as especificidades da Educação do Campo não são consideradas. O Egresso I (2019) enfatiza que "esse campo de conhecimento ainda há muitos entraves, as oportunidades para atuar nessa área são poucas pelo menos até o momento". De fato, ainda são muitos desafios acerca da efetivação das políticas públicas para o sujeito da classe da trabalhadora do campo.

Vale relembrar que, os estudantes do Curso de Licenciatura em Educação do Campo não participaram do último ENADE, porque as provas não contemplam as duas habilitações. Elas são específicas ou para Artes Visuais ou para Música.

Um breve levantamento dos editais de seleção lançados na região em que estão localizados alguns dos estudantes comprova as observações feitas pelos alunos. Apresentemos sinteticamente os editais e as áreas previstas: A Prefeitura 
Municipal de Paranã lançou edital ( ${ }^{\circ}$ 01/2019) de concurso público para preenchimento de 120 vagas em cargos de todos os níveis de escolaridade (fundamental, médio, técnico e superior) na Secretaria Municipal com os seguintes cargos para a área da Educação: Auxiliar de Professor e Assistente Administrativo (nível médio/técnico) e Professor de Pedagogia (nível superior). “Os editais não contemplam o curso de Educação do Campo, pois na minha cidade, Paranã ... houve um concurso e, no entanto, não pude fazer, pois na minha área não tinha absolutamente nada". (Egresso G, LEdoC, 2019).

Outro Concurso Público foi realizado em 2019, unificado para as Prefeituras de Jaú do Tocantins Palmeirópolis/TO e São Salvador do Tocantins/TO. As vagas na área da educação foram: Professor Nível II (formação mínima em Pedagogia e/ou Normal Superior), Professor Nível II (formação em Letras com habilitação em Inglês), Professor Nível II (formação em Educação Física). Os municípios supracitados que realizaram concursos públicos no ano de 2019, são municípios que atendem estudantes da LEdoC e são circunvizinhos a Arraias - TO, onde situa o Campus Universitário.

Além desses, mais um edital $\mathrm{n}^{\circ}$ 01/2020 de concurso público da Prefeitura Municipal de Arraias saiu em (15/01/2020), e não considerou tais habilitações em suas vagas. As vagas na área da educação para nível superior foram: Professor de Língua Portuguesa/Letras e humanas/zona rural; Professor de Matemática e humanas/zona rural Professor Pedagogo/zona rural.

Diante dessa realidade, nos questionamos: como ficam as expectativas de trabalho dos egressos? As respostas dos egressos sobre conhecimento de editais de campo de trabalho na área já demonstram suas frustrações:

Não tenho conhecimento. Dos editais mais recentes que tive a oportunidade de ler eram de concursos municipais os quais não disponibilizaram vagas para áreas específicas, sendo na sua maioria ofertadas nas áreas de Pedagogia. Espero que sejamos contemplados com vagas em concursos estaduais. (Egresso E, LEdoC, 2019).

Sim. No ano de 2019 teve um processo seletivo, em área específica, disponibilizado pelo governo do Estado de Goiás, e nele estava vaga para artes visuais. (Egresso $\mathrm{H}$, LEdoC, 2019).

Dessa forma, acreditamos que os cursos de licenciaturas no Brasil só serão vistos e reconhecidos com essas habilitações se houver por parte dos interessados - principalmente estudantes e professores - discussões acerca disso com os gestores municipais e estaduais de educação, bem como prefeitos e governadores, explicitando a necessidade 
de reconhecê-los nesse processo por meio de leis e decretos.

As legislações educacionais preveem desde 2008 (Lei n ${ }^{\circ}$ 11.769/2008) a inclusão da Música na Educação Básica, no entanto, não houve sua obrigatoriedade como disciplina e sim como conteúdo, o que não impacta também na obrigatoriedade em concursos para licenciados em Música. Ademais, o Programa de Apoio à Formação Superior em Licenciatura em Educação do Campo (Procampo), que apoia e implementa os cursos de LEdoC nas Instituições de Ensino Superior (IES) de todo o país, prevê especificamente a formação de educadores para a docência nos anos finais do ensino fundamental e ensino médio nas escolas rurais. Sendo assim, em muitos concursos para os anos iniciais do ensino fundamental, essas habilitações não são discutidas e inseridas, e sim a formação de Pedagogia - que nem sempre consegue contemplar os elementos para o trabalho com música nessa fase.

Para além dessa iniciativa, talvez fosse interessante o colegiado pensar em principiar uma discussão sobre as habilitações. Uma ideia seria os estudantes, na metade do curso, poderem optar por uma habilitação de seu interesse: Artes Visuais ou Música. Dessa forma, os egressos teriam uma oportunidade maior na inserção e aprofundar seus estudos na habitação para qual escolheu. É uma proposta possível, dado que existem outras Licenciaturas em Educação do Campo no Brasil que trabalham nessa perspectiva, como por exemplo, o Curso de Licenciatura em Educação do Campo ofertado na Universidade Federal do Triângulo Mineiro, que possibilita ao estudante a escolha de duas habilitações Licenciatura em Matemática e/ou Licenciatura em Ciências da Natureza.

Segundo o Projeto Pedagógico do curso (PPC) da referida IES (2019), a escolha da habilitação é realizada no terceiro semestre do curso, podendo haver, ao término desta etapa a complementação para a segunda habilitação. Nessa estruturação, o estudante tem a oportunidade, caso seja do seu interesse, de ter outra habilitação por meio da complementação dentro da própria instituição e curso, obtendo duas habilitações específicas e/ou podendo se dedicar a uma que possua mais afinidade.

No que se refere à contribuição do curso para a vida dos sujeitos da classe trabalhadora, tanto para os estudantes como egressos, é explícito como este possibilita a construção do conhecimento. Podemos verificar isso na fala de um dos egressos:

O curso de Educação do Campo, pra mim foi um divisor de águas na minha vida, pois me emancipei como 
pessoa, como profissional. Antes do curso, eu era uma pessoa que tinha vergonha da minha origem, não gostava de falar que era do campo, que morava no campo, então, tinha vergonha de assumir a própria identidade. E hoje tenho orgulho da minha origem, me conscientizei a partir do aprendizado que adquiri no curso, porque o curso, nos ensinamentos, estava focado na valorização das tradições, da cultura né, dos conhecimentos populares, então aquilo foi fazendo com que eu fosse me emancipando e fosse deixando de lado a vergonha que eu tinha de assumir a minha própria identidade. Hoje, me considero uma pessoa apta a ensina e também a aprender com meus alunos, uma troca mútua de conhecimentos populares como científicos; que no caso, essa junção é de grande valia para o meu crescimento profissional e pessoal. (Egresso A, LEdoC, 2019).

Uma das vantagens desse curso de Licenciatura em Educação do Campo consiste na possibilidade de construção do conhecimento de maneira contrahegemônica, pois a materialização do curso nessa perspectiva pode colaborar muito para que os sujeitos possam observar, ver, pensar e agir de forma diferente em relação aos vários conceitos arraigados na história da humanidade. Conceitos estes, por exemplo, sobre sua própria identidade, a educação e as contradições existentes em nossa sociedade.

Como já dito em outras partes desta pesquisa, o processo de escolarização da educação, principalmente a básica, camufla muitas verdades às vezes inconscientemente, por falta de conhecimento dos educadores e isso de certa forma, interfere na formação do sujeito como um todo, contribuindo para que ele continue sendo passivo, aceitando tudo, como se fosse algo natural da própria sociedade.

Vejamos a análise da importância nas palavras de outro egresso:

Ele só veio a somar. Aumentar ainda mais os meus conhecimentos porque antes de ingressar no curso eu já tinha feito alguns cursinhos sabe, principalmente voltados para Educação do Campo, porque muitos tem uma visão errônea da Educação do Campo... aí eles começam a confundir isso. Coloca educação rural, educação urbana, educação do campo e para o campo. Então, arruma uma confusão muito grande. Quando eu comecei a fazer o curso, a primeira semana que teve aquele seminário integrado já começou aquele impacto muito grande porque eu tive essa diferença da Educação do Campo. Então teve vários questionamentos a respeito disso, aí e abriu muito a minha mente ... hoje, quando alguém me pergunta assim: educação do campo é somete o que? É somente onde você vai mexer com área rural, com animais?... muitas pessoas têm a mente fechado nessa questão. A disciplina você vê, começando com seminário integrado onde você começa a ver ali, a história do homem do campo e aquela imagem que está toda distorcida de quem é o homem do campo é assim. O pessoal da educação do campo precisa ter isso em mente que a educação do campo não é uma coisa que somente vou mexer com animal ali e tal. Não é isso aí. Ela engloba um todo, é muitas coisas juntas. 
Então só veio somar para o meu crescimento, para meus conhecimentos, aumentar minha bagagem de conhecimento. E assim, quanto mais eu aprofundar nesse tema pra mim é melhor porque se uma pessoa chegar e perguntar para mim. Karine fale um pouco de educação do Campo, Educação para o Campo; Educação no Campo - e eu vou ter todas as respostas. É algo que quanto mais a gente puder aprofundar, só veio a somar. (Egresso C, LEdoC, 2019).

Essas considerações mostram 0 quanto essas informações em relação aos sujeitos que vivem no campo - acerca do próprio campo e suas características pairam nas ideias das pessoas de maneira equivocada. Muitas delas ainda acreditam que as pessoas que vivem no campo não precisam de estudos, somente da terra para trabalhar. Em relação a essa questão, já ouvimos várias frases do tipo: "Se você não quiser estudar, vai voltar para roça pra trabalhar"; "Estudar não é para pobre"; entre outras que permeiam a realidade dos camponeses.

A fala de um egresso entrevistado expressa com pontualidade essa questão:

Embora não esteja atuando profissionalmente na área do curso de Licenciatura em Educação do Campo, ressalto algumas contribuições, que afirmo ser de valor inestimável. Durante o meu percurso, enquanto aluna do curso referido, uma gama de conhecimentos até então desconhecidos, ou até mesmo, informações que perpassavam despercebidas, ou mesmo "maquiadas", me foram apresentadas. Obtive a oportunidade de conhecer a alguns fatos históricos sobre a educação, desde o seu surgimento, até a sua organização e aplicação; compreendi como ocorreram e ocorrem até a atualidade algumas injustiças sociais, tais como: a defasagem no ensino, em relação a maneira como a educação em nosso país é imposta. Sendo assim, se fez notável, em alguns casos, o desconhecimento e a falta de criticidade, em relação as lutas dos movimentos sociais e sindicais, suas conquistas e ainda a defasagem do ensino para alguns das classes menos favorecidas, provocada por diversos fatores e entre eles se encontra a falta de apoio por parte dos governantes do nosso país. (Egresso F, LEdoC, 2019).

As falas de alguns egressos demonstram que o curso possibilitou a elevação do conhecimento por vários ângulos, e, os estudantes que participaram das entrevistas relataram que práticas pedagógicas proporcionam a construção de conhecimentos a partir da realidade em vivem: "O curso trouxe grandes benefícios para minha vida pessoal, onde pude adquirir uma visão de mundo mais ampla tanto da área da educação quanto politica, acreditando sempre que o conhecimento pode transformar pessoas e mudar realidades”. (Egresso J, LEdoC, 2019).

Os egressos revelam que o curso da LEdoC proporcionou contribuições importantes à formação pessoal e profissional deles. Muitos disseram que hoje possuem outra visão da "Educação do 
Campo", compreendem que o campo perpassa a ideia equivocada de "lugar atrasado", de "povo atrasado", dentre outros termos muito comuns nos discursos. Entendem, por exemplo, que o Campo é lugar de conhecimento, cultura, diversidade, aprendizado, identidade, enfim da construção de novas possibilidades.

Para Fernandes et al. (2004, p. 137), o campo é:

... lugar de vida, onde as pessoas podem morar, trabalhar, estudar com dignidade de quem tem o seu lugar, a sua identidade cultural. O campo não é só o lugar da produção agropecuária e agroindustrial, do latifúndio e da grilagem de terra. $\mathrm{O}$ campo é espaço e território dos camponeses e dos quilombolas.

Essa compreensão é fundamental para a formação de professores visto que, não só contribui para o reconhecimento da sua identidade, mas pode promover mudanças na formação de pessoas, na medida em que eles forem atuar em escolas localizadas no campo e colocarem em suas práticas pedagógicas conteúdos e discussões sobre esses assuntos, possibilitando que os sujeitos que lá estão compreendam sua história, sua identidade, sua cultura.

Esses apontamentos podem ser verificados também nas palavras do Egresso H (2019): “o curso me ofereceu subsídios para compreender o processo histórico que envolve a complexidade do Campo Brasileiro, e mais autonomia e segurança para profissionalmente desenvolver um bom trabalho a favor dos direitos do homem que vive no campo".

Registramos aqui outras falas que também reforçam essa questão:

Contribuições são relevantes. Pra minha questão profissional foi um curso que me ajudou muito nessa questão de eu voltar, de eu entrar novamente pra pesquisa e também assim trabalhar essa questão da extensão, que até então, nas outras licenciaturas não tive essa oportunidade de ir para o processo de extensão universitária nas pesquisas. E o curso de Educação do Campo me propiciou essa questão da extensão, das pesquisas. Na questão também da entrada no mestrado, ajudou bastante. É um curso que tive a oportunidade de pesquisar e participar de vários congressos, apresentar vários trabalhos, publicar artigos, publicar um capítulo de livro ... (Egresso D, LEdoC, 2019).

O curso de Licenciatura em Educação do Campo contribuiu significativamente para a minha formação pessoal e profissional. Eu venho de uma primeira Licenciatura em Matemática (2008). Porém, eu vim entender o que é um artigo, uma resenha e até mesmo uma monografia no curso de Educação do Campo, onde eu tive professores bem capacitados. Além disso, o contato com as artes visuais e com a música despertaram em mim um outro lado que não conhecia. Apreciar uma tela e ouvir uma boa música passaram a fazer parte da minha vida desde então. Sem falar no gosto pelo violão que pra mim é como se fosse uma terapia. (Egresso E, LEdoC, 2019). 
Por outro lado, há egressos que já perceberam a lacuna na formação de professores por área de conhecimento ao tentar se inserir no mundo do trabalho, como podemos verificar na fala a seguir:

... o curso é muito bom, trouxe muitas contribuições enquanto pessoa, mas como profissional infelizmente não tem área de atuação no mercado de trabalho; eu particularmente tive que tentar uma pós para ver se consigo algum emprego, pois não tem demanda no mercado de trabalho. (Egresso G, LEdoC, 2019).

Concordamos com o egresso em relação às contribuições do curso para vida pessoal, no que se refere à demanda de atuação nas áreas de habilitação Artes Visuais e Música, discordamos em partes; há necessidade (demanda) desse profissional visto que, na maioria das escolas públicas essas áreas são trabalhadas por outros profissionais (com licenciaturas em Letras, Geografia, História e outras). O que falta de fato é o reconhecimento dos professores na Educação do Campo e o cumprimento da exigência da formação específica dos docentes para atuarem com a área da Arte. Ademais, é importante registrar que a região é um polo educacional e que onde existe um determinado curso, tão logo as primeiras turmas se formam, já preenchem a demanda local. Além das 360 (trezentas e sessenta) vagas que obrigatoriamente teriam que ser ofertadas, de acordo com o edital da LEdoC, outras 200 (duzentas) vagas já foram ofertadas, totalizando 560 até final de 2019. Esse número ultrapassa qualquer demanda local e regional.

Sobre as contribuições, outro egresso também destaca:

São várias contribuições, por mais que seja um campo de estudo novo e também onde o mercado de trabalho para essa área ainda é pouco, esse curso é bastante produtivo e agrega vários conhecimentos e oportunidades futuras para a vida profissional e pessoal; além de oferecer duas habilitações no caso Artes Visuais e Música. Mas no geral é um curso excelente; a única questão que deixa a desejar são as poucas opções no mercado de trabalho. (Egresso I, LEdoC, 2019).

Esses relatos mostram que conseguir reconhecimento e trabalhar na área de formação ainda é uma das grandes dificuldades dos egressos e, isso demanda dos interessados, iniciativas para colocar esse assunto em pauta nas discussões com o objetivo de construir ações concretas para os formados não somente do curso de LEdoC da UFT/Arraias, mas também para os de outras LEdoCs de todo o Brasil.

\section{Tecendo algumas considerações}

A partir das discussões realizadas na presente pesquisa, foi possível constatarmos que a educação brasileira é 
desenvolvida - em muitos espaços e perspectivas - nos moldes dos interesses da lógica do sistema neoliberal, e não consegue ainda ser de fato o principal instrumento para reverter esse modelo hegemônico. Todavia, deve ser compreendida como uma ferramenta de enfrentamento contra o capital que se alastra na sociedade, aumentando o abismo social existente entre pobres e ricos. Esse enfrentamento dar-se-á por meio da reflexão dos sujeitos sobre as condições materiais de sua realidade e ao relacionálas para compreender e interferir de maneira consciente que não basta conhecer as relações sociais da sociedade capitalista; é preciso intervir nela para que haja transformação social (Marx, 1973).

Assim sendo, a Educação no Campo deve ser pensada e praticada como uma proposta que possibilita a difusão do conhecimento acumulado pela humanidade, em que estabelece práxis pedagógicas relacionadas a partir dos interesses dos sujeitos do campo, contrapondo-se aos da classe dominante e ao modo de produção capitalista.

A falta de algumas condições basilares para a efetivação da educação de qualidade (como transporte estudantil precário, número insuficientes de professores qualificados, currículo dos programas não ideais às diferentes realidades, quantidade não satisfatória de materiais pedagógicos, problemas com a qualidade na merenda escolar etc.), são características que ainda permeiam a realidade dos sujeitos que vivem no campo. Embora já tenham ocorrido algumas mudanças, a efetivação das políticas públicas ainda não se consolidou para esse espaço, repercutindo negativamente na vida desses sujeitos.

No que concerne aos avanços alcançados, insere-se o curso de Licenciatura em Educação do Campo Educação que, a priori, não resolverá todos os problemas e mazelas que ocorrem na vida da classe trabalhadora do campo. No entanto, constitui-se como uma ação efetiva para o atendimento desses sujeitos, no sentido da acessibilidade de conhecimentos construídos pela humanidade, buscando a consciência de classe, contribuindo para sua emancipação a partir da realidade concreta.

A Educação da classe trabalhadora a partir dessas posturas não só possibilita uma formação mais concreta, como também contribui para a construção de uma sociedade menos desigual.

O curso possui como pressuposto uma formação de educadores ancorada na contextualização e transformação a partir da realidade. Sobretudo, concebe o processo de ensino e de aprendizagem a 
partir de pressupostos da Educação por Alternância, evidenciando aspectos de formação humana numa perspectiva emancipadora capaz de interferir na vida dos sujeitos que vivem no e do campo, contribuindo assim para a transformação da sociedade local.

Nesse sentido, os resultados dessa pesquisa nos permitem tecer algumas considerações sobre os estudantes que compõem a LEdoC. A primeira é que o modelo que o curso adota atualmente, como pontuado pelos entrevistados, permite a dinamicidade da mediação e interlocução/compartilhamento do conhecimento no curso e se aproxima de fato de uma Educação por Alternância. Isso porque, o processo de articulação dos saberes nos TU e TC está se consolidando, possibilitando assim, uma apreensão maior dos conteúdos propostos como, elaborado no PPC (UFT, 2013) de curso em análise.

É inegável que o curso de Licenciatura em Educação do Campo possibilita a classe trabalhadora do campo o acesso à educação superior. No entanto, a expansão de cursos voltados para essa população - que é diversa em vários aspectos - apresenta alguns entraves inerentes ao perfil dos alunos, uma vez que muitos desses estudantes são mães e pais de famílias que necessitam do trabalho para sua sobrevivência. Diante disso, conciliar o trabalho e estudo é o desafio para muitos para se chegar até o diploma.

Quando retomamos

O questionamento da introdução desta pesquisa: Quais são perspectivas dos egressos da LEdoC da UFT/campus de Arraias, Tocantins? Em relação aos egressos da LEdoC, analisamos que o número de estudantes que concluíram ainda não é expressivo, pois de acordo com os dados coletados, somente 37 (trinta e sete) sujeitos concluíram o curso. Por outro lado, os egressos revelam que o curso da LEdoC proporcionou contribuições importantes à formação pessoal, uma vez que muitos disseram que hoje têm outra visão da "Educação do Campo". Nessa nova percepção, compreendem que o campo perpassa a ideia equivocada de "lugar atrasado", de "povo atrasado", dentre outros termos negativos e preconceituosos. Entendem que o Campo é lugar de conhecimento, cultura, diversidade, aprendizado e identidade, afinal é o lugar da construção das novas possibilidades.

Quanto à inserção ao mundo trabalho, o curso (e suas especificidades) ainda não está sendo contemplado em editais de seleções e concursos, tanto municipais como estaduais, o que exige uma atenção sobre essas questões por parte principalmente dos interessados. 
Diante dos dados apresentados nesse estudo, é possível perceber que a LEdoC se empenha para que de fato sua proposta se materialize de forma satisfatória, no entanto, possui muitos desafios ainda. Esta pesquisa também nos possibilitou compreender que a educação é condicionada a vários fatores, dentre eles, os que se referem à questão de estrutura e infraestrutura da sociedade.

Assim, entendemos que o curso de Licenciatura em Educação do Campo apresenta essas condicionalidades bem mais enfáticas para sua materialização por se tratar de pessoas da classe trabalhadora e, ainda, do campo, bem como serem de localidades diversas da sede do campus universitário.

É importante ressaltar que o cenário atual é incerto (2021) pelo fato de algumas políticas públicas educacionais estarem sendo ameaçadas nesses últimos anos e isso, por sua vez, afeta diretamente a consolidação das LEdoCs. Entende-se que as lutas da classe trabalhadora foram importantes para a conquista de alguns direitos, no entanto, é preciso mais do que urgente resistir às ações contrárias a essa classe (como foi a extinção da SECADI/MEC), no sentido de pelo menos garantir a conservação de alguns direitos sociais, dentre eles o do acesso (e da permanência) à educação com qualidade.
Nesse desiderato, pode-se dizer que a realização desta pesquisa foi de grande importância para compreender melhor a concepção histórica, política e epistemológica na dinâmica de formação de professores para atuarem em escolas no campo, além de contribuir com as discussões sobre os desafios e perspectivas da educação superior no âmbito da Educação no Campo. Em síntese, este texto não tem a pretensão de esgotar a análise em curso, mas suscitar inquietações na busca para a melhoria de sua qualidade.

\section{Referências}

Aires, H. Q. P. (2020). Análise dos desafios e perspectivas do curso de Licenciatura em Educação do Campo, campus de Arraias, Estado do Tocantins (Tese de Doutorado). Universidade Federal de São Carlos, São Paulo.

Brasil (2002). Resolução CNE/CEB 1, de 3 de abril de 2002. Institui as Diretrizes Operacionais para a Educação Básica nas Escolas do Campo. Brasília. Recuperado de

http://portal.mec.gov.br/index.php?option= com_docman\&view=download\&alias $=138$ 00-rceb001-02pdf\&category_slug=agosto-2013pdf\&Itemid=30192.

Brasil. Lei $n^{\circ} 11.769$, de 18 de Agosto de 2008. Altera a Lei $n^{\circ}$ 9.394, de 20 de dezembro de 1996, Lei de Diretrizes e Bases da Educação, para dispor sobre a obrigatoriedade do ensino da música na educação básica. http://www.planalto.gov.br/ccivil_03/_ato2 007-2010/2008/lei/l11769.htm 
Brito, M. M. B., \& Molina, M. C. (2016). Estudo com egressos da Licenciatura em Educação do Campo da UNB no contexto da expansão da educação superior. In Anais do XXIV Seminário Nacional UNIVERSITAS. (pp. 1723-1746). Recuperado de http://www.ppe.uem.br/xxivuniversitas/ana is/trabalhos/e_7/7-012.pdf

Fernandes, B. M. (2004). Diretrizes de uma caminhada. In Arroyo, M. G., Caldart, R. S., \& Molina, M. C. (Orgs.). Por uma educação do campo (pp. 133-158). Petrópolis: Vozes.

Gadotti, M. (2001). A dialética: concepção e método. In Gadotti, M. Concepção dialética da educação (pp. 15-38). São Paulo: Cortez/Autores Associados.

Locatelli, A. S., Nunes, K. C. S., \& Pereira, F. A. (2013). Educação do campo no estado do Tocantins: desafios pedagógicos e curriculares. Revista Espaço do Currículo, 6(3), 583-594.

Martins, L. M. (2006). As aparências enganam: divergências entre o materialismo histórico dialético $e$ as abordagens qualitativas de pesquisa. GT: Filosofia da Educação/17. In Anais Reunião Anual da ANPED, 29, pp. 1-17. Recuperado de http://29reuniao.anped.org.br/trabalhos/tra balho/GT17-2042--Int.pdf

Marx, K. (1973). Contribuição para a crítica da economia política. Lisboa: Estampa.

Masson, G. (2012). As contribuições do método materialista histórico e dialético para a pesquisa sobre políticas educacionais. In IX ANPED SUL. Seminário de Pesquisas em Educação da Região Sul. Recuperado de http://www.ucs.br/etc/conferencias/index.p hp/anpedsul/\%209anpedsul/paper/viewFile /966/126
Molina, M. C. (2017). Contribuições das Licenciaturas em Educação do Campo para as políticas de formação de educadores. Educação \& Sociedade, 38(140), 587-609. https://doi.org/10.1590/ES0101$\underline{73302017181170}$

Oliveira, M. E. B. (2017). Educação do Campo, políticas públicas e movimentos sociais: o papel do Pronera na construção de autonomias relativas. In Foschiera, A. A., Cabral, J. P. C., \& Cerqueira, O. N. (Orgs.). Educação do Campo e o campo de atuação da Escola Família Agrícola de Porto Nacional-TO: Pronera, Agroecologia e Camponeses (pp. 15-42). Palmas: Nagô.

Ribeiro, M. (2013). Política educacional para populações camponesas: da aparência à essência. Revista Brasileira de Educação, 18(54), 669-691. https://doi.org/10.1590/S1413$\underline{24782013000300009}$

Saviani, D. (2008). Escola e democracia. Campinas: Autores Associados.

Universidade Federal do Tocantins (2013). Projeto Político Pedagógico do Curso de Licenciatura em Educação do Campo: Códigos e Linguagens - Artes Visuais e Música. Arraias: UFT. Recuperado de http://download.uft.edu.br/?d=2b2b330c2a4c-4065-93d3-dc1e7975728d:052014\%20-

\footnotetext{
i Deposição da Presidente da República Dilma Rousseff pelo Congresso Nacional.
} 


\begin{abstract}
Informações do Artigo I Article Information
Recebido em : 04/08/2021

Aprovado em: 12/10/2021

Publicado em: 13/11/2021

Received on August 04th, 2021

Accepted on October 12th, 2021

Published on November, 13th, 2021

Contribuições no Artigo: Os(as) autores(as) foram os(as) responsáveis por todas as etapas e resultados da pesquisa, a saber: elaboração, análise e interpretação dos dados; escrita e revisão do conteúdo do manuscrito e; aprovação da versão final publicada.
\end{abstract}

Author Contributions: The author were responsible for the designing, delineating, analyzing and interpreting the data, production of the manuscript, critical revision of the content and approval of the final version published.

Conflitos de Interesse: Os(as) autores(as) declararam não haver nenhum conflito de interesse referente a este artigo.

Conflict of Interest: None reported.

\title{
Avaliação do artigo
}

Artigo avaliado por pares.

\section{Article Peer Review}

Double review.

\section{Agência de Fomento}

Não tem.

\section{Funding}

No funding.

\section{Como citar este artigo / How to cite this article}

APA

Aires, H. Q. P., \& Bezerra Neto, L. (2021). Perspectivas dos egressos do Curso de Licenciatura em Educação do Campo, Campus Arraias/Tocantins. Rev. Bras. Educ.
Camp.,
6 ,
e12819.

http://dx.doi.org/10.20873/uft.rbec.e12819

\section{ABNT}

AIRES, H. Q. P.; BEZERRA NETO, L. Perspectivas dos egressos do Curso de Licenciatura em Educação do Campo, Campus Arraias/Tocantins. Rev. Bras. Educ. Camp., Tocantinópolis, v. 6, e12819, 2021. http://dx.doi.org/10.20873/uft.rbec.e12819 